Published in final edited form as:

J Am Chem Soc. 2019 July 31; 141(30): 12139-12146. doi:10.1021/jacs.9b05926.

\title{
The Elusive 5'-Deoxyadenosyl Radical: Captured and Characterized by Electron Paramagnetic Resonance and Electron Nuclear Double Resonance Spectroscopies
}

\author{
Hao Yang ${ }^{\dagger}$, Elizabeth C. McDaniel ${ }^{\ddagger}$, Stella Impano ${ }^{\ddagger}$, Amanda S. Byer ${ }^{\ddagger}$, Richard J. Jodts ${ }^{\dagger}$, \\ Kenichi Yokoyama§, William E. Broderick ${ }^{\ddagger}$, Joan B. Broderick ${ }^{\star}, \ddagger$, Brian M. Hoffman ${ }^{\star}, \dagger$ \\ †Department of Chemistry, Northwestern University, Evanston, Illinois 60208, United States \\ ‡Department of Chemistry and Biochemistry, Montana State University, Bozeman, Montana \\ 59717, United States \\ §Department of Biochemistry, Duke University, Durham, North Carolina 27710, United States
}

\begin{abstract}
The $5^{\prime}$-deoxyadenosyl radical ( $5^{\prime}$-dAdo $)$ abstracts a substrate $\mathrm{H}$ atom as the first step in radicalbased transformations catalyzed by adenosylcobalamin-dependent and radical $S$-adenosyl-Lmethionine (RS) enzymes. Notwithstanding its central biological role, $5^{\prime}$-dAdo has eluded characterization despite efforts spanning more than a half-century. Here, we report generation of $5^{\prime}$-dAdo in a RS enzyme active site at $12 \mathrm{~K}$ using a novel approach involving cryogenic photoinduced electron transfer from the $[4 \mathrm{Fe}-4 \mathrm{~S}]^{+}$cluster to the coordinated $S$ adenosylmethionine (SAM) to induce homolytic $\mathrm{S}-\mathrm{C}^{\prime}{ }^{\prime}$ bond cleavage. We unequivocally reveal the structure of this long-sought radical species through the use of electron paramagnetic resonance (EPR) and electron nuclear double resonance (ENDOR) spectroscopies with isotopic labeling, complemented by density-functional computations: a planar $\mathrm{C} 5^{\prime}(2 \mathrm{p} \pi)$ radical $(\sim 70 \%$ spin occupancy); the $\mathrm{C} 5^{\prime}(\mathrm{H})_{2}$ plane is rotated by $\sim 37^{\circ}$ (experiment) $39^{\circ}$ (DFT) relative to the $\mathrm{C} 5^{\prime}-\mathrm{C} 4^{\prime}-\left(\mathrm{C} 4^{\prime}-\mathrm{H}\right)$ plane, placing a $\mathrm{C}^{\prime}-\mathrm{H}$ antiperiplanar to the ribose-ring oxygen, which helps stabilize the radical against elimination of the $4^{\prime}-\mathrm{H}$. The agreement between $\varphi$ from experiment and in vacuo DFT indicates that the conformation is intrinsic to 5-dAdo. itself, and not determined by its environment.
\end{abstract}

\section{Graphical Abstract}

\footnotetext{
*Corresponding Authors: jbroderick@montana.edu, bmh@ northwestern.edu. Supporting Information

The Supporting Information is available free of charge on the ACS Publications website at DOI: 10.1021/jacs.9b05926. Additional methods; X-band EPR spectra; simulations of X-band FT-EPR spectra; hyperfine tensors of $5^{\prime}$-dAdo·; DFT calculations; comparison of hyperfine couplings calculated with B3LYP and BP86 functionals; DFT calculated energy; Q-band EPR spectra and simulations; CW stochastic ${ }^{13}$ C ENDOR; XPR spectra (PDF)

The authors declare no competing financial interest.
} 


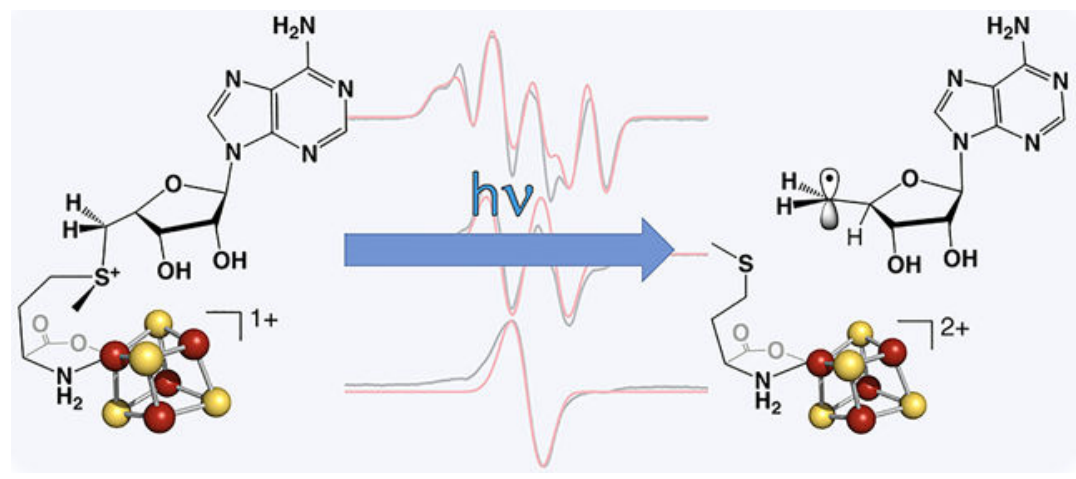

\section{INTRODUCTION}

The discovery by Barker et al. in 1958 of a cobalamin involved in catalyzing an isomerization reaction, ${ }^{1}$ and its subsequent identification as adenosylcobalamin (coenzyme $\mathrm{B}_{12}$ (Figure 1)) by Lenhert and Hodgkin in $1961,{ }^{2}$ set the stage for decades of study focused on the biochemical reactions of this remarkable organometallic cofactor. We now know that coenzyme $\mathrm{B}_{12}$ serves as a reversible radical generator, undergoing $\mathrm{Co}-\mathrm{C}$ bond homolysis to give a $5^{\prime}$-deoxyadenosyl radical $\left(5^{\prime}\right.$-dAdo $)$ that initiates chemistry by $\mathrm{H}$ atom abstraction from a substrate. ${ }^{3}$ The involvement of $5^{\prime}$-dAdo has been shown primarily through label transfer studies, for example, by observing the incorporation of substrate deuterons into adenosylcobalamin during catalysis. ${ }^{4-6}$ Important insights into its behavior have been attained through kinetic and spectroscopic investigations in which the $\mathrm{Co}-\mathrm{C}^{\prime}$ bond of $\mathrm{B}_{12}$ is photolytically cleaved, after which the $5^{\prime}$-dAdo- radical can either reform that bond or proceed to react with substrate. ${ }^{7,8}$ However, strenuous efforts over many years ${ }^{9}$ to trap and fully characterize the $5^{\prime}$-dAdo formed from $\mathrm{B}_{12}$ have been unavailing: the radical has simply been too reactive to trap.

The significance of the $5^{\prime}$-dAdo radical in biology broadened dramatically with the recognition that $S$-adenosyl-L-methionine (SAM) plays a role analogous to that of coenzyme $\mathrm{B}_{12}$ in initiating radical reactions. ${ }^{10,11}$ This role for SAM was first suggested for lysine 2,3aminomutase ${ }^{12,13}$ and pyruvate formate-lyase activating enzyme (PFL-AE), ${ }^{14,15}$ but it is now implicated throughout the vast and diverse radical SAM (RS) superfamily. ${ }^{16-19}$ Until recently, the accepted mechanism for the RS enzymes involved SAM coordination to the unique iron of the $[4 \mathrm{Fe}-4 \mathrm{~S}]$ cluster in the active site; electron transfer from the reduced $[4 \mathrm{Fe}-4 \mathrm{~S}]^{+}$cluster to SAM promotes reductive cleavage of SAM to give methionine and $5^{\prime}-$ dAdo., which initiates chemistry via substrate $\mathrm{H}$ atom abstraction. ${ }^{16,20-22}$ The recent discovery of the catalytically competent organometallic intermediate $\Omega$ formed during the RS reaction provides a new twist on the mechanism by implicating a coenzyme $\mathrm{B}_{12}$-like organometallic intermediate with an $\mathrm{Fe}-\mathrm{C} 5^{\prime}$ bond that undergoes homolytic bond cleavage to release $5^{\prime}$-dAdo..$^{20,23,24}$

Insights into the characteristics of the $5^{\prime}$-dAdo radical intermediate in RS enzymes have been achieved via the SAM analog $3^{\prime}, 4^{\prime}$-anhydro- $S$-adenosylmethionine (anSAM), which generates an allylically stabilized $5^{\prime}$-dAdo analog that is amenable to characterization, ${ }^{25,26}$ 
but the $5^{\prime}$-dAdo radical is so extraordinarily reactive that so far attempts to generate and characterize this radical itself have not been productive. For example, photolysis of coenzyme $\mathrm{B}_{12}$ in frozen solution appears to produce $5^{\prime}$-dAdo', but spin-spin interactions between the $\mathrm{Co}(\mathrm{II} ; S=1 / 2$ ) corrinoid and the $S=1 / 2$ radical result in a broad, poorly defined electron paramagnetic resonance (EPR) signal that is not amenable to analysis. ${ }^{27} \mathrm{~A}$ sharp fluid-solution FT-EPR spectrum acquired upon photolysis of $\mathrm{B}_{12}$ and thought to arise from $5^{\prime}$-dAdo is instead the result of rapid radical rearrangement rather than $5^{\prime}$-dAdo. itself (see SI Text and Figure S2). ${ }^{28}$ An organic radical that accumulates during the reaction of the RS enzyme spore photoproduct lyase with SAM at $40{ }^{\circ} \mathrm{C}$ also has been proposed to be $5^{\prime}$ dAdo $\cdot{ }^{29}$ but we show in the Supporting Information that this radical too is not $5^{\prime}$-dAdo. (see SI Text, Figure S3, and Table S1).

Here, after more than half a century of efforts by numerous investigators to trap and characterize the biologically central $5^{\prime}$-dAdo radical, we demonstrate the formation of $5^{\prime}$ dAdo in a RS enzyme active site by using a novel approach involving photoinitiated electron transfer from the reduced $[4 \mathrm{Fe}-4 \mathrm{~S}]^{+}$cluster to the coordinated SAM. The resulting $5^{\prime}$-dAdo is definitively identified through the use of isotopically labeled SAM combined with EPR and electron nuclear double resonance (ENDOR) spectroscopy, with its structure analyzed using density functional theory (DFT) computation.

\section{EXPERIMENTAL METHODS}

\section{Materials.}

[Methyl- ${ }^{13} \mathrm{C}$ ]-L-methionine, ${ }^{15} \mathrm{~N}$-L-methionine, and 2,8- $\mathrm{D}_{2}-1^{\prime}, 2^{\prime}, 3^{\prime}, 4^{\prime}, 5^{\prime}, 5^{\prime \prime}$ - $\mathrm{D}_{6}$-adenosine $5^{\prime}$-triphosphate salt solution were purchased from Cambridge Isotope Laboratories, Inc. $\left[{ }^{13} \mathrm{C}_{10},{ }^{15} \mathrm{~N}_{5}\right]$-Adenosine $5^{\prime}$-triphosphate sodium salt solution was purchased from Sigma, and 3,3,4,4-L-methionine- $d_{4}$ was obtained from CDN Isotopes.

\section{Protein and SAM Preparation.}

PFL-AE, unlabeled SAM, and labeled SAMs were prepared as previously reported. ${ }^{30}$

\section{Photolysis.}

PFL-AE was prepared for photolysis by reducing the enzyme and adding labeled or unlabeled SAM. Photoreduced PFL-AE was prepared as previously described ${ }^{30}$ with minor alterations. PFL-AE (0.55 mM), dithiothreitol (DTT, $1.0 \mathrm{mM})$, and deazariboflavin (200 $\mu \mathrm{M}$, dissolved in DMSO) were combined in buffer (50 mM Tris, $100 \mathrm{mM} \mathrm{KCl,} \mathrm{pH} \mathrm{7.5)} \mathrm{in} \mathrm{an}$ anaerobic COY chamber. The sample was irradiated by a $500 \mathrm{~W}$ halogen lamp for $1 \mathrm{~h}$ while the samples remained in an ice water bath. Labeled or unlabeled SAM $(5.5 \mathrm{mM})$ was then added. The samples were then transferred to EPR tubes and frozen in liquid nitrogen inside the COY chamber.

Dithionite reductions were performed similarly as follows: PFL-AE (0.55 mM), DTT (1.0 $\mathrm{mM})$, and sodium dithionite $(3.0 \mathrm{mM})$ were combined in an anaerobic COY chamber and allowed to sit $3 \mathrm{~min}$ before SAM $(5.5 \mathrm{mM})$ was added. The samples were flash frozen as described above and stored in liquid nitrogen. 
Photolysis was carried out in situ using a $450 \mathrm{~nm}$ Thorlabs diode laser. The time course of $12 \mathrm{~K}$ photolysis of ( $\mathrm{PFL}-\mathrm{AE}^{1+}+\mathrm{SAM}$ ) complex was monitored during intracavity photolysis in an X-band EPR spectrometer. The in situ photolysis of the (PFL-AE $\left.{ }^{1+}+\mathrm{SAM}\right)$ complex prereduced to the $[4 \mathrm{Fe}-4 \mathrm{~S}]^{+}$state using either deazariboflavin or dithionite gives identical EPR spectra, Figure S1. The in situ photolyzed samples were subjected to X- and Q-band CW EPR and Q-band ENDOR measurements as described below.

\section{EPR and ENDOR Measurements.}

X-band continuous wave (CW) EPR spectroscopy was conducted on a Bruker ESP 300 spectrometer equipped with an Oxford Instruments ESR 910, while Q-band CW EPR spectroscopy was conducted on a Bruker EMX spectrometer equipped with an Oxford Instruments Mercury iTC continuous helium flow cryostat. Typical experimental parameters were at 12 and $40 \mathrm{~K}, 9.38$ or $34.0 \mathrm{GHz}$, and $10 \mathrm{G}$ modulation amplitude. EPR simulations were performed with the EasySpin ${ }^{5.2 .23}$ program operating in Matlab. ${ }^{31}$

$35 \mathrm{GHz} \mathrm{CW}$ and pulse ENDOR spectroscopic data were collected on spectrometers, described previously, ${ }^{32-34}$ that are equipped with liquid helium immersion dewars for measurements at $2 \mathrm{~K}$. The $\mathrm{CW}$ measurements employed $100 \mathrm{kHz}$ field modulation and dispersion-mode detection under rapid passage conditions. ${ }^{1} \mathrm{H}$ CW ENDOR spectra employed bandwidth broadening of the RF to $100 \mathrm{kHz}$ to improve signal-to-noise. ${ }^{35}{ }^{1} \mathrm{H} \mathrm{CW}$ ENDOR spectra were collected using the stochastic-field modulation detected ENDOR sequence $^{36}$ to improve ENDOR line shape. For a single molecular orientation and for nuclei with a nuclear spin of $I=1 / 2\left({ }^{13} \mathrm{C}\right)$, the ENDOR transitions for the $m_{\mathrm{s}}= \pm 1 / 2$ electron manifolds are observed to be first order as shown in the equation:

$$
v_{ \pm}=\left|v_{n} \pm \frac{A}{2}\right|
$$

where $v_{n}$ is the nuclear Larmor frequency and $A$ is the orientation-dependent hyperfine coupling. When $v_{n}>A / 2$, the pattern is a doublet split by $A$ and centered at $v_{n}$; when $v_{n}<$ $A / 2$, the pattern is a doublet centered at $A / 2$ and split by $2 v_{n}$.

\section{DFT Calculations.}

All DFT computations of $5^{\prime}$-dAdo - were performed in ORCA 4.0.1. ${ }^{37}$ Initial coordinates for the $5^{\prime}$-dAdo fragment were taken from two structures: PFL-AE (2.77 ̊̊ resolution) with SAM bound to the $[4 \mathrm{Fe}-4 \mathrm{~S}]$ cluster (PDB $3 \mathrm{CB} 8)^{38}$ and a $1.15 \AA$ resolution crystal structure of a SAM-dependent methyltransferase (PDB 3DLC). All protein residues, water, and other molecules were removed, and the adenine was replaced with a methyl group. Hydrogens were added appropriately to the structure with the unbiased starting geometry of the $5^{\prime}-\mathrm{CH}_{2}$ hydrogens being in a pseudotetrahedral conformation. Both geometry optimizations and single-point calculations used the spin unrestricted $\mathrm{B} 3 \mathrm{LYP}^{39-41}$ hybrid functional and the Ahlrichs' valence triple- $\xi$ with a polarization function basis set. ${ }^{42}$ The molecular orbitals were visualized as Gaussian cubes and an isosurface of 0.08 au in Pymol. Hyperfine and $\mathbf{g}$ tensors were calculated by the coupled-perturbed self-consistent field (SCF) approach as implemented in ORCA 4.0 using the B3LYP hybrid functional and EPR-III basis ${ }^{43,44}$ in 
combination with the accurate spin-orbit coupling operator [RI-SOMF(1X)] ${ }^{45}$ Calculations using the $\mathrm{BP} 86^{39}$ functional were carried out in parallel.

The optimized structures and all energetic and spectroscopic output parameters for $5^{\prime}$-dAdo. are identical for the two starting points. The results presented are those from the highresolution structure. Similar results are obtained for the two functionals, as shown in Table S2.

\section{RESULTS}

\section{Photolysis of PFL-AE/[4Fe-4S] ${ }^{+} /$SAM.}

The present study was indirectly prompted by the idea that the $\mathrm{Fe}-\mathrm{C} 5^{\prime}$ bond of the $\Omega^{23,24}$ intermediate in RS enzymes might be cleaved photolytically, similar to the $\mathrm{Co}-\mathrm{C} 5^{\prime}$ bond of coenzyme $\mathrm{B}_{12}$. If this were to occur, then photoinitiated homolysis of $\Omega$ would produce the diamagnetic $[4 \mathrm{Fe}-4 \mathrm{~S}]^{2+}$ cluster and the sought-after $5^{\prime}$-dAdo radical. However, because sulfoniums have been reported to be photochemically reactive, ${ }^{46,47}$ we first carried out control experiments in which SAM and PFL-AE/[4Fe-4S $]^{1+}$ were combined and photolyzed in the absence of substrate PFL, circumstances in which SAM is not enzymatically cleaved and $\Omega$ does not form. Much to our surprise, irradiation of such samples in the EPR cavity at $450 \mathrm{~nm}$ and $12 \mathrm{~K}$ results in rapid conversion of the SAM-bound $[4 \mathrm{Fe}-4 \mathrm{~S}]^{+}$state of PFL-AE (Figure 2A) to one with a new free-radical signal that is partially saturated and thus poorly resolved at $12 \mathrm{~K}$, Figure 2B, but becomes well-resolved at $40 \mathrm{~K}$ (Figure 3A). A time course of the photolysis shows the loss of the $[4 \mathrm{Fe}-4 \mathrm{~S}]^{1+}$ signal directly correlates with the appearance of the new radical signal (Figure 2C).

The data is consistent with photoinduced electron transfer (ET) from the $[4 \mathrm{Fe}-4 \mathrm{~S}]^{+}$cluster to $\mathrm{SAM},{ }^{48}$ providing the EPR-silent $[4 \mathrm{Fe}-4 \mathrm{~S}]^{2+}$ cluster and a SAM-derived organic cryotrapped radical to study; such photoinduced ET has not previously been reported for RS enzymes. On the basis of known RS enzyme chemistry, the most likely identity of the new radical species would be the $5^{\prime}$-dAdo radical, resulting from reductive cleavage of SAM. However, other forms for the trapped radical are possible. ${ }^{49}$ Rearrangement to form a $4^{\prime}$ radical or even a cyclo-adenosine radical must be considered, and if the highly reactive $5^{\prime}$ dAdo is formed, it might have attacked a nearby protein residue to generate a protein radical, even at $12 \mathrm{~K}$. We therefore pursued detailed studies that unequivocally identify the structure of this radical species.

The radical as trapped in the active site of PFL-AE is stable at $77 \mathrm{~K}$ and below but is lost upon annealing for $1 \mathrm{~min}$ at $150 \mathrm{~K}$. Figure $3 \mathrm{~A}$ shows that the EPR spectrum of the radical species under nonsaturating conditions $(40 \mathrm{~K})$ can be well simulated by incorporating ${ }^{1} \mathrm{H}$ hyperfine interactions appropriate for trapped $5^{\prime}$-dAdo, Figure $3 \mathrm{~A}$. The simulation ${ }^{31}$ includes anisotropic hyperfine couplings to two near-equivalent $a$-type ${ }^{1} \mathrm{H}$ on $5^{\prime}$-C plus coupling to one near-isotropic $\beta$-type ${ }^{1} \mathrm{H}$ on $4^{\prime}$-C; the hyperfine tensors are reported in Table 1. The two resulting $a$-type ${ }^{1} \mathrm{H}$ hyperfine tensor components, confirmed and refined as described below, have values roughly in the ratio of $\sim 1 / 2 / 3$, as expected for a trigonalplanar, $\mathrm{C} a-{ }^{1} \mathrm{H}$ carbon radical, and indeed quantitatively agree quite well with those of the $\mathrm{Ca}-{ }^{1} \mathrm{H}$ radical of $\cdot \mathrm{CH}(\mathrm{COOH})_{2}$ formed by irradiation of malonic acid (Table 1). In addition, 
it is well-established ${ }^{50-52}$ that a $\beta$-type ${ }^{1} \mathrm{H}$, such as the ${ }^{1} \mathrm{H}-4^{\prime}-\mathrm{C}$ of $5^{\prime} \mathrm{dAdo}$, gives a large, near-isotropic coupling, as observed here (Table 1). The Q-band EPR spectrum (Figure 3F) is equally well simulated with these parameters and has the additional benefit of enhancing the influence of the small free-radical g-anisotropy, which helped refine both the $\mathbf{g}$ and hyperfine tensors (Table 1). Of particular note as an "internal check", the intermediate hyperfine component of an $a$-proton must lie parallel to the $2 \mathrm{p} \pi$ orbital, which is in turn parallel to $\mathrm{g}_{3} \approx \mathrm{ge}^{50-54}$ and, thus, must be parallel for the two $a$-protons of $5^{\prime} \mathrm{dAdo}$. This was required for the optimized simulations of the radical spectra, particularly the Q-band spectrum (Table 1), even though the tensors were determined without imposing this as a prior constraint.

\section{Confirmation of Radical Species Using SAM Isotopologs.}

To confirm this new radical species as the $5^{\prime}$-dAdo radical and to refine its ${ }^{1} \mathrm{H}$ hyperfine interaction parameters, we carried out photolysis experiments utilizing isotopically labeled SAMs ${ }^{30}$ Assignment of the $a$-type couplings to the two $5^{\prime}-\mathrm{C} a$ protons is confirmed by the collapse of both the X-band (Figure 3B) and Q-band (Figure S5) spectra of the radical generated with [adenosyl- $5^{\prime}, 5^{\prime \prime}-\mathrm{D}_{2}$ ]-SAM to a doublet resulting from the near-isotropic splitting from the $4^{\prime}-\mathrm{C} \beta$ proton. This splitting in turn is lost in both the X-band and Q-band spectra of the radical generated with the perdeuterated-Ado SAM isotopologue ([adenosyl-2,8- $\left.\mathrm{D}_{2}-1^{\prime}, 2^{\prime}, 3^{\prime}, 4^{\prime}, 5^{\prime}, 5^{\prime \prime}-\mathrm{D}_{6}\right]-\mathrm{SAM}$ ) (Figures 3C and S5). Together, these measurements show that the radical formed by photolysis is indeed the long-sought $5^{\prime}$ dAdo.

This identification is further confirmed, and the characterization of $5^{\prime}$-dAdo is strengthened and enriched by the examination of the radical formed with ${ }^{13} \mathrm{C}$ isotopologues. When prepared with [adenosyl- ${ }^{13} \mathrm{C}_{10},{ }^{15} \mathrm{~N}_{5}$ ]-SAM (Figure 3D), the radical X-band EPR spectrum shows additional splittings from two ${ }^{13} \mathrm{C}$, one with the anisotropic hyperfine tensor expected ${ }^{50-52}$ for the $5^{\prime}-{ }^{13} \mathrm{Ca}$ " $\mathrm{sp}^{2}$ " carbon and one with the smaller, nearly isotropic coupling expected for the $4^{\prime}-{ }^{13} \mathrm{C} \beta$ carbon (Table 1). The assignment of the two couplings to their respective carbons is confirmed by the EPR spectrum of radical prepared from singly labeled $5^{\prime}-{ }^{13} \mathrm{C} \mathrm{SAM}$ (Figure 3E), which shows the splittings with the anisotropic tensor assigned to $5^{\prime}-{ }^{13} \mathrm{Ca}$ (Table 1 ). Note that the maximum ${ }^{13} \mathrm{C}$ coupling for a spin in a carbon $2 \mathrm{p} \pi$ orbital must also lie along $\mathrm{g}_{3}=\mathrm{g}_{\mathrm{e}},{ }^{50-52}$ as found experimentally for $5^{\prime}-{ }^{13} \mathrm{C}$, without prior constraint (Table 1).

The Q-band ENDOR spectra for $5^{\prime}-{ }^{13} \mathrm{C}-\mathrm{SAM}$, Figure 3G, shows a peak centered at a frequency corresponding to approximately $A_{3} / 2$ of $5{ }^{\prime}-{ }^{13} \mathrm{C}$ (Table 1). The Q-band ENDOR spectra from the radical prepared from [adenosyl- ${ }^{13} \mathrm{C}_{10},{ }^{15} \mathrm{~N}_{5}$ ] SAM (Figure $3 \mathrm{G}$ ) show not only the $5^{\prime}-{ }^{13} \mathrm{C}$ signal but also a signal from the near-isotropically coupled $3{ }^{\prime}-{ }^{13} \mathrm{C}$ centered at a frequency determined by essentially half its isotropic coupling (Table 1), as well as a doublet with a much weaker coupling $(A=0.8 \mathrm{MHz})$ assigned to $1{ }^{\prime}-{ }^{13} \mathrm{C}$ and/or $2{ }^{\prime}-{ }^{13} \mathrm{C}$; the signal from $4{ }^{\prime}-{ }^{13} \mathrm{C}$ is hidden under the ${ }^{1} \mathrm{H}$ ENDOR response from weakly coupled protons (Figure $\mathrm{S} 6$ ). These ${ }^{13} \mathrm{C}$ measurements unambiguously confirm the photochemically generated radical is indeed $5^{\prime}$-dAdo. 


\section{Structure of $5^{\prime}$-dAdo.}

Beyond the identification of $5^{\prime} \mathrm{dAdo}$, the observed hyperfine interactions teach us about its electronic and geometric structure. The two ${ }^{1} \mathrm{Ha}$ and the $5{ }^{\prime}-{ }^{13} \mathrm{C} a$ coupling tensors are in good agreement with those for the odd electron in the $2 \mathrm{p} \pi$ orbital of the planar $\left(\mathrm{sp}^{2}\right)$ carboncentered radical of X irradiated malonic acid (Table 1). ${ }^{54}$ The match, notably in the isotropic couplings, indicates that the spin density in the $2 \mathrm{p} \pi$ orbital on $\mathrm{C}^{\prime}$ of $5^{\prime}-\mathrm{dAdo} \cdot\left(\rho_{\pi}\right)$ is comparable to that in malonic acid, $\rho_{\pi} \sim 0.7$. Of particular note, the spin-polarizationinduced isotropic coupling of the $2 \mathrm{p} \pi$ spin of planar ${ }^{13} \mathrm{C}^{\prime}$ would have been sharply increased by a pseudotetrahedral "doming" distortion at $\mathrm{C} 5^{\prime}$, which would introduce $2 \mathrm{~s}$ character, with its large isotropic coupling, ${ }^{51}$ into the odd-electron orbital. Thus, we infer that the $\mathrm{H}_{2}-\mathrm{C}^{\prime}-\mathrm{C} 4^{\prime}$ fragment is essentially planar. The isotropic coupling of a proton $\beta$ to a carbon $2 \mathrm{p} \pi$ electron spin, such as ${ }^{1} \mathrm{H}-\mathrm{C} 4^{\prime}$, is known to obey the relationship, $a_{\text {iso }} \approx$ $\rho_{\pi} \mathrm{B} \cos ^{2} \varphi \mathrm{MHz}$, where $B$ reflects the transmission of spin to ${ }^{1} \mathrm{H}$ through hyper-conjugation, $\rho_{\pi} B \approx 140 \mathrm{MHz}$, and $\varphi$ is the dihedral angle between the $2 \mathrm{p} \pi$ orbital and the $\mathrm{C} \beta-\mathrm{H}$ bond, ${ }^{51}$ corresponding to the angle between the $\left[4^{\prime} \mathrm{CH}-4^{\prime} \mathrm{C}-5^{\prime} \mathrm{C}\right]$ plane and of the $2 \mathrm{p} \pi$ orbital (normal to the plane formed by $\mathrm{C}^{\prime}$ and its two $\mathrm{H}$ atoms). Applying this relationship to the measured ${ }^{1} \mathrm{H}-\mathrm{C} 4^{\prime}$ isotropic coupling (Table 1) yields a value of $\varphi \approx 37^{\circ}$.

These conclusions from the experimental finding are confirmed and extended by DFT computations ${ }^{37}$ for $5^{\prime}$-dAdo. (Table S2 and Figure S4). First, the computations yield an energy-minimized structure that reproduces the observed hyperfine couplings extremely well, Table 1 , with a value for the spin density in the C $5^{\prime} 2 \mathrm{p} \pi$ orbital of $\rho_{\pi}=0.7$, in agreement with the experimental analysis. The computations further generate the radical's structure (Figure 4, top), which exhibits both a rigorously planar geometry at $\mathrm{C} 5^{\prime}$ and a dihedral "twist" at the $\mathrm{C}^{\prime}-\mathrm{C} 4^{\prime}$ bond, as inferred above. The dihedral (twist) angle in the energy-minimized geometry $\varphi \approx 39^{\circ}$ (Figure 4 , bottom) is quite close to that indicated by the experimental analysis above and creates a structure with a $\mathrm{C}^{\prime}-\mathrm{H}$ antiperiplanar to the oxygen of the ribose ring, which helps stabilize the radical against elimination of $4^{\prime}-\mathrm{H}$, as suggested long ago. ${ }^{57}$ The agreement between $\varphi$ determined experimentally for $5^{\prime}$-dAdo. in the active site of a frozen enzyme and $\varphi$ from DFT of the radical in vacuo indicates that the dihedral angle is determined by interactions within the radical itself, not by those with its environment.

\section{$5^{\prime}$-dAdo in the Active Site.}

Expanding our focus, the use of additional SAM isotopologues gives a sense of the relationship of the SAM fragments ( $5^{\prime}$-dAdo and Met) subsequent to homolysis. When $5^{\prime}$ dAdo is prepared from [3,3,4,4-methionine- $\left.\mathrm{D}_{4}\right]$-SAM, subtle changes in the shape of the EPR spectrum (Figure S7) indicate that the apparent EPR line width of the naturalabundance spectrum includes the effects of weak hyperfine couplings to protons of the methionine side chain. In contrast, there are no changes in the EPR spectrum when prepared from $\mathrm{CD}_{3}$-methyl or ${ }^{13} \mathrm{C}$-methyl methionine $\mathrm{SAM}$, and no weakly coupled ${ }^{13} \mathrm{C}$ ENDOR signal is introduced by the ${ }^{13} \mathrm{C}$ substitution (Figure S7), indicating the radical site is remote from the methyl group. These observations indicate that, upon SAM S-C $5^{\prime}$ homolytic bond cleavage, the $\mathrm{C} 5{ }^{\prime}$ radical has shifted toward the methionine $\mathrm{C} 3$ and $\mathrm{C} 4$ and away from the methyl, as illustrated schematically in Figure 5. Such a movement leaves the spin-bearing 
$\mathrm{C}^{\prime}$ in proximity to the methionine side chain, allowing unresolved hyperfine couplings to those hydrogens to influence the EPR spectrum, yet removed enough from the methionine ${ }^{13} \mathrm{C}$-methyl so as to leave no detectable couplings to that nucleus in either EPR or ENDOR spectra.

\section{DISCUSSION}

The $5^{\prime}$-dAdo- radical is the central species responsible for $\mathrm{H}$ atom abstraction from the substrate in both coenzyme $\mathrm{B}_{12}$ and the large RS superfamily of enzymes, but until now, it had eluded characterization. In the present work, we generated the $5^{\prime}$-dAdo- radical in PFL$\mathrm{AE}$ by cryogenic photoinduced electron transfer (ET) from the $[4 \mathrm{Fe}-4 \mathrm{~S}]^{1+}$ to $\mathrm{SAM}$, causing reductive cleavage of SAM to generate the $5^{\prime}$-dAdo radical, and methionine chelated to the diamagnetic $[4 \mathrm{Fe}-4 \mathrm{~S}]^{2+}$ cluster. Because the cluster is diamagnetic, there are no spin-spin interactions that would interfere with the characterization of the photogenerated radical, and its assignment as $5^{\prime}$ dAdo has been unequivocally established through the use of ${ }^{13} \mathrm{C}$ and ${ }^{2} \mathrm{H}$ labels.

Our early ENDOR studies showed that, in the absence of PFL substrate, SAM is coordinated to the reduced PFL-AE $[4 \mathrm{Fe}-4 \mathrm{~S}]^{1+}$ cluster through the amino acid group of SAM with the sulfonium in close contact to the cluster $(<4 \AA) .{ }^{58,59}$ Thus, this photoinduced ET is analogous to the inner-sphere ET thought to occur during enzymatic catalysis, ${ }^{58,60}$ with key roles being played by configurational interaction between donor and acceptor orbitals on the sulfonium and the PFL-AE/[4Fe-4S $]^{1+}$ cluster, ${ }^{61}$ conformational and electronic influences of substrate binding, ${ }^{62}$ and the mechanistic requirement of $\Omega$ formation. ${ }^{20,23,24}$ Why, then, is $5^{\prime}$-dAdo, rather than $\Omega$, produced in the current experiments? One possible answer is that $\Omega$ formation might require the conformational consequences of the presence of substrate. Unfortunately, we have not yet been able to test this hypothesis because adding substrate to the PFL-AE/[4Fe-4S $]^{1+} / \mathrm{SAM}$ complex leads to immediate substrate turnover. ${ }^{60}$ Even when $\mathrm{PFL}-\mathrm{AE} /[4 \mathrm{Fe}-4 \mathrm{~S}]^{1+}$, SAM, and substrate are combined in rapid-freeze quench experiments with short deadtimes, $\Omega$ is formed and $5^{\prime}$-dAdo. is not observed. In other words, the enzymatic turnover system appears to be designed to avoid the production of free dAdo- and rather to form the more stable $5^{\prime}$-dAdo precursor $\Omega$. As we have previously postulated, ${ }^{25}$ the highly reactive $5^{\prime}$-dAdo is never free under normal catalytic conditions.

An additional consideration is the nature of the process of electron transfer and SAM cleavage itself. During catalysis, RS enzymes must overcome a large potential barrier for reductive cleavage of SAM, due to the mismatch in reduction potentials between $\mathrm{RS}$ [4Fe$4 \mathrm{~S}]^{1+}$ clusters $(-400 \text { to }-600 \mathrm{mV})^{63-67}$ and SAM (estimated as $\left.\sim-1.8 \mathrm{~V}\right) .{ }^{68,69}$ The binding of SAM and substrate in the active site is thought to perturb both potentials, lowering the barrier to reductive SAM cleavage. ${ }^{62}$ RS catalysis via formation of $\Omega$ likely also lowers the barrier to this cleavage through the stabilization contributed by the $\mathrm{Fe}-\mathrm{C} 5^{\prime}$ bond formation, thus providing a favorable alternative pathway to direct SAM cleavage by simple ET to form $5^{\prime}$-dAdo $\cdot .^{20,23,24}$

The photoinduced ET reported here instead uses photon energy to overcome the barrier to direct the formation of $5^{\prime}$-dAdo. While understanding the precise nature of this process will 
require further study, prior studies of photoreduction by metal centers ${ }^{70}$ suggest that in the present study the photon excites the cluster to a ligand-to-metal charge transfer (LMCT) excited state, which quickly relaxes to a relatively long-lived $[4 \mathrm{Fe}-4 \mathrm{~S}]^{1+}$ ligand field excited state that is a potent and effective electron donor. In short, the energy of the incident photon, as captured in an ET-reactive excited state, is sufficient to enable the direct formation of $5^{\prime}$ dAdo by S-C5' homolysis without the formation of $\Omega$.

\section{CONCLUSION}

In summary, after more than half a century of attempts, the primary-carbon $5^{\prime}$-dAdo- radical has at last been captured, and its electronic and geometric structure has been characterized by multifrequency EPR, Q-band ENDOR, and DFT computation. The capture without radical rearrangement was accomplished via cryogenic (12 K), intra-EPR-cavity, photoinduced ET from the PFL-AE $[4 \mathrm{Fe}-4 \mathrm{~S}]^{1+}$ to cluster-bound SAM, triggering reductive cleavage of SAM to generate the $5^{\prime}$ dAdo- cryo-trapped radical along with the diamagnetic $[4 \mathrm{Fe}-4 \mathrm{~S}]^{2+}$ cluster. The facile and efficient nature of this photo-induced ET, not previously reported for any radical SAM enzyme, raises the intriguing question of whether photoinitiated reactions might play an as-yet unrecognized role in RS enzymes or other catalytic systems involving iron-sulfur clusters. Perhaps the most surprising finding about $5^{\prime}$-dAdo. itself is the absence of surprises: its remarkable reactivity accompanies properties that are almost precisely as foundational studies of organic radicals long ago would have predicted.

\section{Supplementary Material}

Refer to Web version on PubMed Central for supplementary material.

\section{ACKNOWLEDGMENTS}

We gratefully acknowledge the support of the NIH (GM 111097 to B.M.H.; GM 54608 to J.B.B.).

\section{REFERENCES}

(1). Barker HA; Weissbach H; Smyth RD A coenzyme containing pseudovitamin B12. Proc. Natl. Acad. Sci. U. S. A 1958, 44, 1093-1097. [PubMed: 16590317]

(2). Lenhert PG; Hodgkin DC Structure of the 5,6-dimethylbenzimidazolylcobamide coenzyme. Nature 1961, 192, 937-938. [PubMed: 14463985]

(3). Halpern J Mechanisms of Coenzyme B12-Dependent Rearrangements. Science 1985, 227, 869875. [PubMed: 2857503]

(4). Brown KL Chemistry and Enzymology of Vitamin B12. Chem. Rev 2005, 105, 2075-2149. [PubMed: 15941210]

(5). Banerjee R; Ragsdale SW The many faces of vitamine B12: Catalysis by cobalamin-dependent enzymes. Annu. Rev. Biochem 2003, 72, 209-247. [PubMed: 14527323]

(6). Frey PA; Abeles RH The role of the B12 coenzyme in the conversion of 1,2-propanediol to propionaldehyde. J. Biol. Chem 1966, 241, 2732-2733. [PubMed: 5911645]

(7). Jones AR The photochemistry and photobiology of vitamin B12. Photochem. Photobiol. Sci 2017, 16, 820-834. [PubMed: 28463378]

(8). Rury AS; Wiley TE; Sension R Energy cascades, escited state dynamics, and photochemistry in cob(III)alamins and ferric porphyrins. Acc. Chem. Res 2015, 48, 860-867. [PubMed: 25741574]

(9). Hogenkamp HPC; Barker HA; Mason HS An electron-spin resonance study of coenzyme B12. Arch. Biochem. Biophys 1963, 100, 353-359. [PubMed: 13964013] 
(10). Frey PA Lysine 2,3-aminomutase: is adenosylmethionine a poor man's adenosylcobalamin? FASEB J. 1993, 7, 662-670. [PubMed: 8500691]

(11). Frey PA; Magnusson OT S-Adenosylmethionine: A wolf in sheep's clothing, or a rich man's adenosylcobalamin? Chem. Rev 2003, 103, 2129-2148. [PubMed: 12797826]

(12). Moss M; Frey PA The role of S-adenosylmethionine in the lysine 2,3-aminomutase reaction. J. Biol. Chem 1987, 262, 14859-14862. [PubMed: 3117791]

(13). Baraniak J; Moss ML; Frey PA Lysine 2,3-aminomutase. Support for a mechanism of hydrogen transfer involving S-adenosylmethionine. J. Biol. Chem 1989, 264, 1357-1360. [PubMed: 2492274]

(14). Knappe J; Schmitt T A novel reaction of S-adenosyl-Lmethionine correlated with the activation of pyruvate formate-lyase. Biochem. Biophys. Res. Commun 1976, 71, 1110-1117. [PubMed: 971302]

(15). Frey M; Rothe M; Wagner AFV; Knappe J Adenosylmethionine-dependent synthesis of the glycyl radical in pyruvate formate-lyase by abstraction of the glycine C-2 pro-S hydrogen atom. J. Biol. Chem 1994, 269, 12432-12437. [PubMed: 8175649]

(16). Broderick JB; Duffus BR; Duschene KS; Shepard EM Radical S-Adenosylmethionine Enzymes. Chem. Rev 2014, 114, 4229-4317. [PubMed: 24476342]

(17). Bridwell-Rabb J; Grell TAJ; Drennan CL A rich man, poor man story of S-adebosylmethionine and cobalamin revisited. Annu. Rev. Biochem 2018, 87, 555-584. [PubMed: 29925255]

(18). Landgraf BJ; McCarthy EL; Booker SJ Radical S-adenosylmethionine enzymes in human health and disease. Annu. Rev. Biochem 2016, 85, 485-514. [PubMed: 27145839]

(19). Holliday GL; Akiva E; Meng EC; Brown SD; Calhoun S; Pieper U; Sali A; Booker SJ; Babbitt PC Atlas of the radical SAM superfamily: Divergent evolution of function using a "Plug and Play" domain. Methods Enzymol. 2018, 606, 1-71. [PubMed: 30097089]

(20). Broderick WE; Hoffman BM; Broderick JB Mechanism of Radical Initiation in the Radical SAdenosyl-1-methionine Superfamily. Acc. Chem. Res 2018, 51, 2611-2619. [PubMed: 30346729]

(21). Frey PA Travels with carbon-centered radicals. $5^{\prime}$ deoxyadenosine and $5^{\prime}$-deoxyadenosine- $5^{\prime}$-yl in radical enzymology. Acc. Chem. Res 2014, 47, 540-549. [PubMed: 24308628]

(22). Frey PA; Hegeman AD; Reed GH Free radical mechanisms in enzymology. Chem. Rev 2006, 106, 3302-3316. [PubMed: 16895329]

(23). Horitani M; Shisler KA; Broderick WE; Hutcheson RU; Duschene KS; Marts AR; Hoffman BM; Broderick JB Radical SAM catalysis via an organometallic intermediate with an $\mathrm{Fe}\left[5^{\prime}-\mathrm{C}\right]-$ deoxyadenosyl bond. Science 2016, 352, 822-825. [PubMed: 27174986]

(24). Byer AS; Yang H; McDaniel EC; Kathiresan V; Impano S; Pagnier A; Watts H; Denler C; Vagstad AL; Piel J; Duschene KS; Shepard EM; Shields TP; Scott LG; Lilla EA; Yokoyama K; Broderick WE; Hoffman BM; Broderick JB Paradigm shift for radical S-adenosyl-L-methionine reactions: The organometallic intermediate $\Omega$ is central to catalysis. J. Am. Chem. Soc 2018, 140, 8634-8638. [PubMed: 29954180]

(25). Horitani M; Byer AS; Shisler KA; Chandra T; Broderick JB; Hoffman BM Why Nature Uses Radical SAM Enzymes so Widely: Electron Nuclear Double Resonance Studies of Lysine 2,3Aminomutase Show the 5' -dAdo "Free Radical" is Never Free. J. Am. Chem. Soc 2015, 137, 7111-7121. [PubMed: 25923449]

(26). Magnusson OT; Reed GH; Frey PA Spectroscopic Evidence for the participation of an allylic analogue of the $5^{\prime}$-deoxyadenosyl radical in the reaction of lysine 2,3-aminomutase. J. Am. Chem. Soc 1999, 121, 9764-9765.

(27). Ghanekar VD; Lin RJ; Coffman RE; et al. Detection by electron spin resonance of an exchangecoupled cob(II)alamin $\cdots$ free radical pair species generated by anaerobic photolysis of polycrystalline adenosylcobalamin. Biochem. Biophys. Res. Commun 1981, 101, 215-221. [PubMed: 6269545]

(28). Bussandri AP; Kiarie CW; Van Willigen H Photoinduced bond homolysis of B12 coenzymes. An FT-EPR study. Res. Chem. Intermed 2002, 28, 697-710. 
(29). Heidinger L; Kneuttinger AC; Kashiwazaki G; Weber S; Carell T; Schleicher E Direct observation of a deoxyadenosyl radical in an active enzyme environment. FEBS Lett. 2016, 590, 4489-4494. [PubMed: 27878994]

(30). Byer AS; McDaniel EC; Impano S; Broderick WE; Broderick JB Mechanistic Studies of Radical SAM Enzymes: Pyruvate Formate-Lyase Activating Enzyme and Lysine 2,3-Aminomutase Case Studies. Methods Enzymol. 2018, 606, 269-318. [PubMed: 30097096]

(31). Stoll S; Schweiger A EasySpin, a comprehensive software package for spectral simulation and analysis in EPR. J. Magn. Reson 2006, 178, 42-55. [PubMed: 16188474]

(32). Werst MM; Davoust CE; Hoffman BM Ligand Spin Densities in Blue Copper Proteins by Q-band 1H and 14N ENDOR Spectroscopy. J. Am. Chem. Soc 1991, 113, 1533-1538.

(33). Zipse H; Artin E; Wnuk S; Lohman GJS; Martino D; Griffin RG; Kacprzak S; Kaupp M; Hoffman B; Bennati M; Stubbe J; Lees N Structure of the nucleotide radical formed during reaction of CDP/TTP with the E441Q-a2b2 of E. coli ribonucleotide reductase. J. Am. Chem. Soc 2009, 131, 200-211. [PubMed: 19128178]

(34). Davoust CE; Doan PE; Hoffman BM Q-Band Pulsed Electron Spin-Echo Spectrometer and Its Application to ENDOR and ESEEM. J. Magn. Reson., Ser. A 1996, 119, 38-44.

(35). Hoffman BM; DeRose VJ; Ong JL; Davoust CE Sensitivity enhancement in field-modulated CW ENDOR via RF bandwidth broadening. J. Magn. Reson., Ser. A 1994, 110, 52-57.

(36). Lee H-I; Igarashi RY; Laryukhin M; Doan PE; Dos Santos PC; Dean DR; Seefeldt LC; Hoffman $\mathrm{BM}$ An organometallic intermediate during alkyne reduction by nitrogenase. J. Am. Chem. Soc 2004, 126, 9563-9569. [PubMed: 15291559]

(37). Neese F The ORCA program system. Comput. Mol. Sci 2012, 2, 73-78.

(38). Vey JL; Yang J; Li M; Broderick WE; Broderick JB; Drennan CL Structural basis for glycyl radical formation by pyruvate formate-lyase activating enzyme. Proc. Natl. Acad. Sci. U. S. A 2008, 105, 16137-16141. [PubMed: 18852451]

(39). Becke AD Density-functional exchange-energy approximation with correct asymptotic behavior. Phys. Rev. A: At., Mol., Opt. Phys 1988, 38, 3098-3100.

(40). Perdew JP Density-functional approximation for the correlation-energy of the inhomogeneous electron-gas. Phys. Rev. B: Condens. Matter Mater. Phys 1986, 33, 8822-8824.

(41). Lee C; Yang W; Parr RG Development of the Colle-Salvetti correlation energy formula into a functional of the electron density. Phys. Rev. B: Condens. Matter Mater. Phys 1988, 37, 785-789.

(42). Schäfer A; Huber C; Ahlrichs R Fully optimized contracted gaussian basis sets of triple zeta valence quality for atoms Li to Kr. J. Chem. Phys 1994, 100, 5829-5835.

(43). Barone V In Recent Advances in Density Functional Methods; World Scientific: Singapore, $1995 ; \mathrm{p} 287$.

(44). Rega N; Cossi M; Barone V J. Chem. Phys 1996, 105, 11060.

(45). Neese F Efficient and accurate approximations to the molecular spin-orbit coupling operator and their use in molecular gtensor calculations. J. Chem. Phys 2005, 122, No. 034107.

(46). Dektar JL; Hacker NP Photochemistry of triarylsulfonium salts. J. Am. Chem. Soc 1990, 112, 6004-6015.

(47). Saeva FD; Morgan BP; Luss HR Photochemical conversion of sulfonium salts to sulfides via a 1,3-sigmatropic rearrangement. Photogeneration of Bronsted acids. J. Org. Chem 1985, 50, 4360-4362.

(48). Mao Z; Liou S-H; Khadka N; Jenney FEJ; Goodin DB; Seefeldt LC; Adams MWW; Cramer SP; Larsen D Cluster-dependent charge-transfer dynamics in iron-sulfur proteins. Biochemistry 2018, 57, 978-990. [PubMed: 29303562]

(49). Jost M; Simpson JH; Drennan CL The transcription factor CarH safeguards use of adenosylcobalamin as a light sensor by altering the photolysis products. Biochemistry 2015, 54, 3231-3234. [PubMed: 25966286]

(50). Weil JA; Bolton JR; Wertz JE Electron Paramagnetic Resonance: Elementary Theory and Practical Applications; John Wiley \& Sons: New York, 1994.

(51). Atherton NM Principles of Electron Spin Resonance; Ellis Horwood: New York, 1993. 
(52). Carrington A; McLachlan AD Introduction to magnetic resonance: with applications to chemistry and chemical physics; Harper and Row: New York, 1967.

(53). McConnell HM; Strathdee J Theory of anisotropic hyperfine interactions in pi-electron radicals. Mol. Phys 1959, 2, 129-138.

(54). Horsfield A; Morton JR; Whiffen DH Electron-spin resonance of gamma-irradiated malonic acid. Mol. Phys 1961, 4, 327-332.

(55). McConnell HM; Heller C; Cole T; Fessenden RW Radiation damage in organic crystals. I. $\mathrm{CH}(\mathrm{COOH}) 2$ in malonic acid. J. Am. Chem. Soc 1960, 82, 766-775.

(56). Cole T; Heller C Hyperfine Splittings in the (HOOC)-C13H(COOH) Radical. J. Chem. Phys 1961, 34, 1085-1086.

(57). Lott WB; Chagovetz AM; Grissom CB Alkyl radical geometry controls geminate cage recombination in alkylcobalamins. J. Am. Chem. Soc 1995, 117, 12194-12201.

(58). Walsby CJ; Hong W; Broderick WE; Cheek J; Ortillo D; Broderick JB; Hoffman BM Electronnuclear double resonance spectroscopic evidence that $\mathrm{S}$-adenosylmethionine binds in contact with the catalytically active $[4 \mathrm{Fe}-4 \mathrm{~S}]^{+}$cluster of pyruvate formate-lyase activating enzyme. $\mathrm{J}$. Am. Chem. Soc 2002, 124, 3143-3151. [PubMed: 11902903]

(59). Walsby CJ; Ortillo D; Broderick WE; Broderick JB; Hoffman BM An anchoring role for FeS Clusters: Chelation of the amino acid moiety of S-adenosylmethionine to the unique iron site of the [4Fe-4S] cluster of pyruvate formate-lyase activating enzyme. J. Am. Chem. Soc 2002, 124, 11270-11271. [PubMed: 12236732]

(60). Henshaw TF; Cheek J; Broderick JB The $[4 \mathrm{Fe}-4 \mathrm{~S}]^{+}$cluster of pyruvate formate-lyase activating enzyme generates the glycyl radical on pyruvate formate-lyase: EPR-detected single turnover. J. Am. Chem. Soc 2000, 122, 8331-8332.

(61). Dey A; Peng Y; Broderick WE; Hedman B; Hodgson KO; Broderick JB; Solomon EI S K-edge XAS and DFT Calculations on SAM Dependent Pyruvate Formate-Lyase Activating Enzyme: Nature of Interaction between the Fe4S4 Cluster and SAM and its Role in Reactivity. J. Am. Chem. Soc 2011, 133, 18656-18662. [PubMed: 21992686]

(62). Wang SC; Frey PA Binding energy in the one-electron reductive cleavage of Sadenosylmethionine in lysine 2,3-aminomutase, a radical SAM enzyme. Biochemistry 2007, 46, 12889-12895. [PubMed: 17944492]

(63). Hinckley GT; Frey PA Cofactor dependence of reduction potentials for [4Fe-4S]2+/1+ in lysine 2,3-aminomutase. Biochemistry 2006, 45, 3219-3225. [PubMed: 16519516]

(64). Ugulava NB; Gibney BR; Jarrett JT Biotin synthase contains two distinct iron-sulfur cluster binding sites: Chemical and spectroelectrochemical analysis of iron-sulfur cluster interconversions. Biochemistry 2001, 40, 8343-8351. [PubMed: 11444981]

(65). Maiocco SJ; Grove TL; Booker SJ; Elliott SJ Electrochemical resolution of the [4Fe-4S] centers of the AdoMet radical enzyme BtrN: Evidence of proton coupling and an unusual, low-potential auxiliary cluster. J. Am. Chem. Soc 2015, 137, 8664-8667. [PubMed: 26088836]

(66). Blaszczyk AJ; Silakov A; Zhang B; Maiocco SJ; Lanz ND; Kelly WL; Elliott SJ; Krebs C; Booker SJ Spectroscopic and electrochemical characterization of the iron-sulfur and cobalamin cofactors of TsrM, an unusual radical S-adenosylmethionine methylase. J. Am. Chem. Soc 2016, 138, 3416-3426. [PubMed: 26841310]

(67). Maiocco SJ; Arcinas AJ; Landgraf BJ; Lee K-H; Booker SJ; Elliott SJ Transformations of the FeS clusters of the methylthiotransferases MiaB and RimO, detected by direct electrochemistry. Biochemistry 2016, 55, 5531-5536. [PubMed: 27598886]

(68). Grimshaw J Electrochemistry of the sulfonium group In Chemistry of the Sulphonium Group; Stirling CJM, Ed.; Wiley: Chichester, 1981; pp 141-155.

(69). Saeva FD; Morgan BP Mechanism of one-electron electrochemical reductive cleavage reactions of sulfonium salts. J. Am. Chem. Soc 1984, 106, 4121-4125.

(70). McCusker JK Electronic structure in the transition metal block and its implications for light harvesting. Science 2019, 363, 484-488. [PubMed: 30705184] 

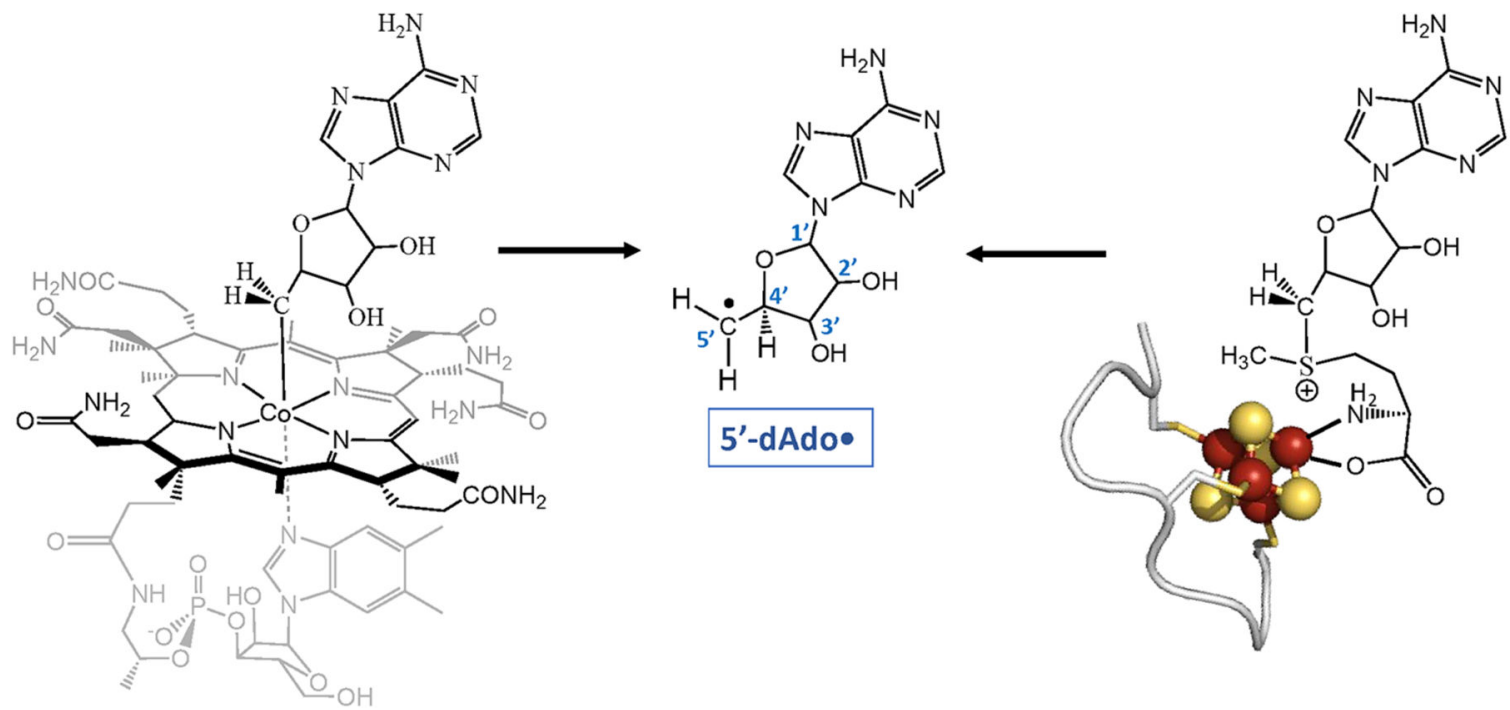

Figure 1.

Adenosylcobalamin/coenzyme $\mathrm{B}_{12}$ (left) and $S$-adenosylmethionine bound to a [4Fe-4S] cluster in the active site of RS enzymes (modeled at right) both serve as precursors to the $5^{\prime}$ dAdo radical intermediate (center). 

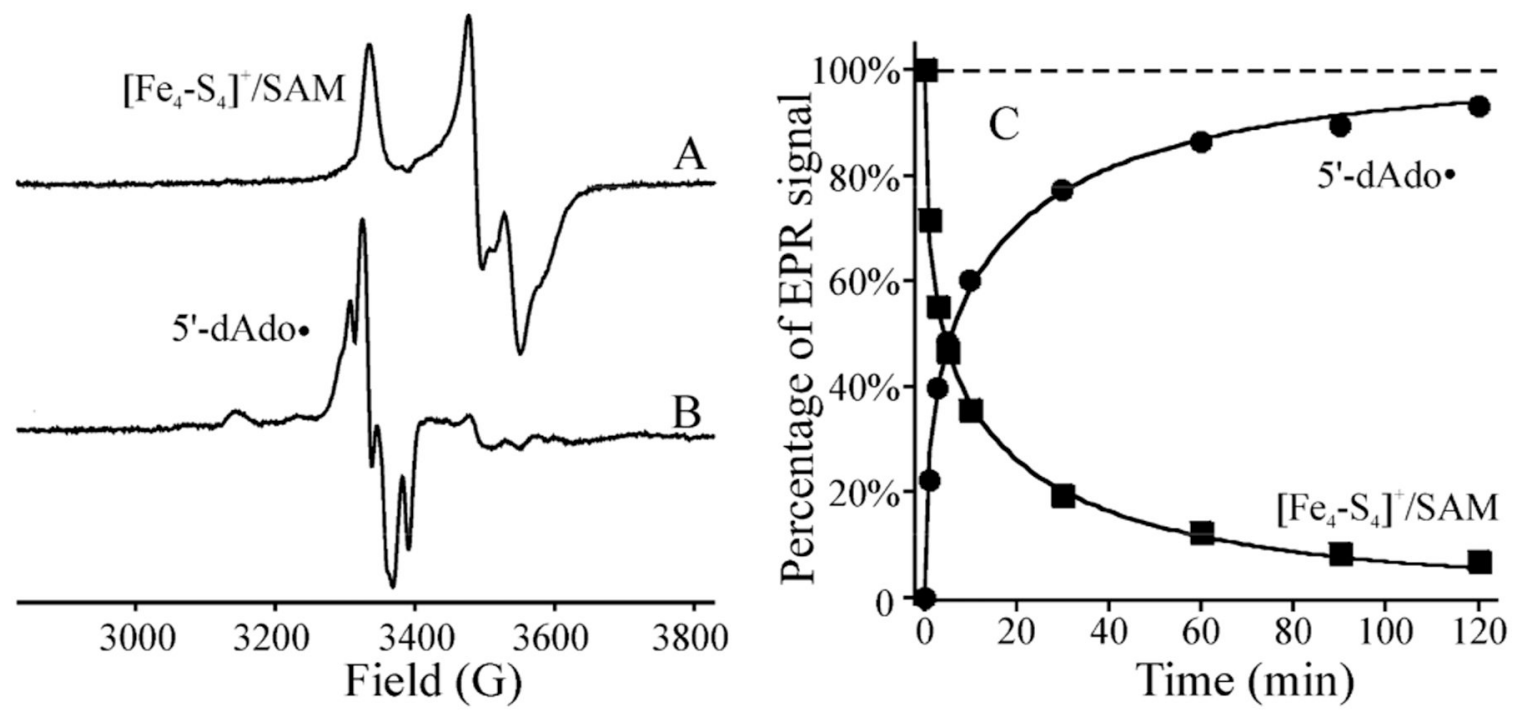

Figure 2.

X-band EPR spectra of the $\left([4 \mathrm{Fe}-4 \mathrm{~S}]^{+}+\mathrm{SAM}\right)$ PFL-AE complex (A) before and (B) after photolysis at $12 \mathrm{~K}$ with $450 \mathrm{~nm}$ LED for $1 \mathrm{~h}$ to produce the $5^{\prime}$-dAdo- radical with nearcomplete loss of the initial complex signal. Conversion is quantitative; residual cluster signal in spectrum B is from the enzyme out of the laser beam. (C) Time course for decay of $\left([4 \mathrm{Fe}-4 \mathrm{~S}]^{+}+\mathrm{SAM}\right)(\boldsymbol{\square})$ upon photolysis monitored at $3600 \mathrm{G}$ and increase of $5^{\prime}$-dAdo $\cdot(\mathbf{O})$ monitored at $3360 \mathrm{G}$. The two progress curves are fit to stretched-exponential (as the result of light scattering within the "snow" samples) decay, $I=\exp \left(-[t / \tau]^{n}\right)$, and rise, $I=1-\exp (-$ $\left.[t / \tau]^{n}\right)$, functions with the same parameters, $\tau=11(1)$ min and $n=0.43(2)$. EPR conditions: microwave frequency, $9.38 \mathrm{GHz}$; modulation, $10 \mathrm{G} ; T, 12 \mathrm{~K}$. 

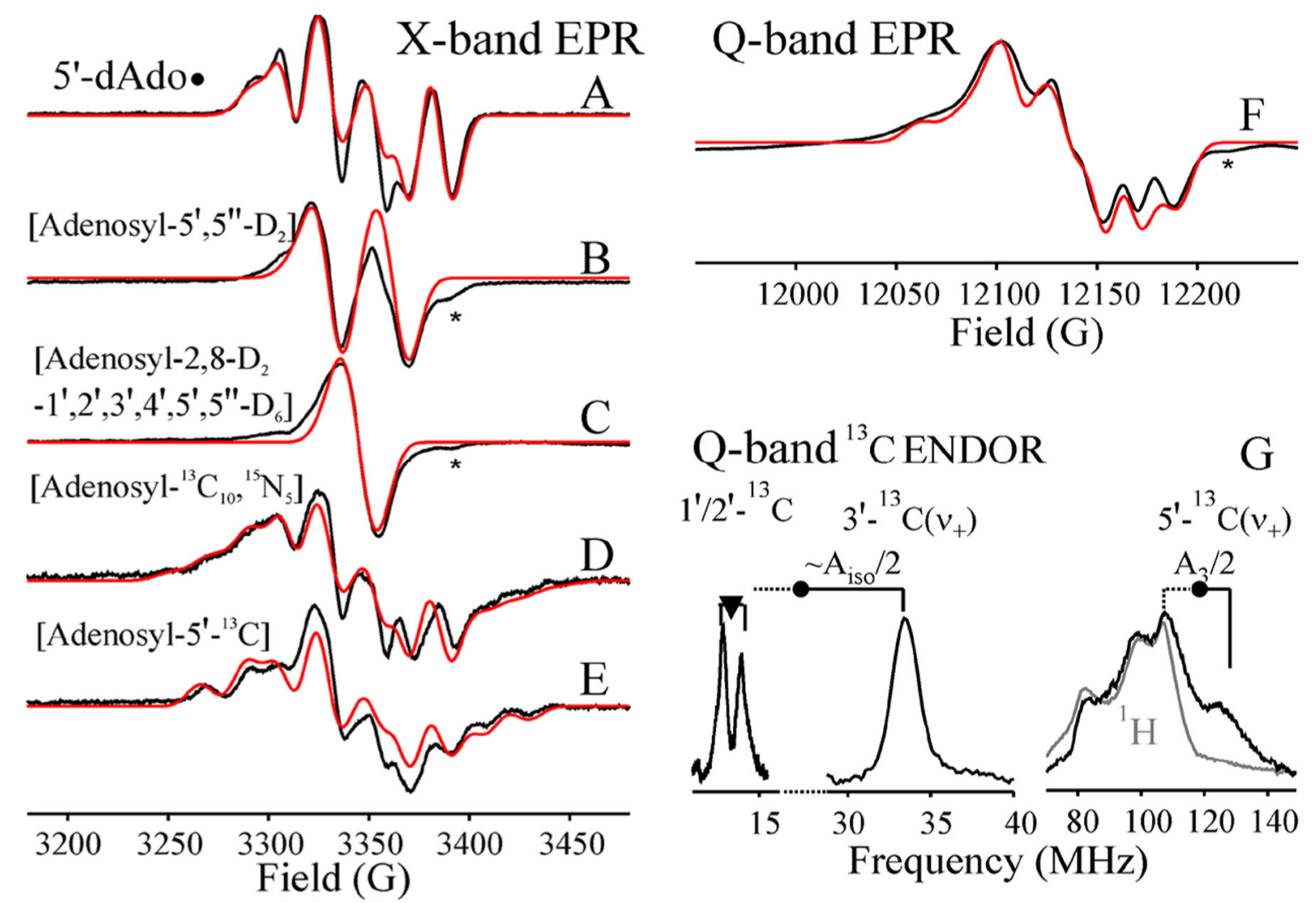

Figure 3.

A-E, X-band EPR spectra (black) and simulations (red) of $5^{\prime}$-dAdo $.5^{\prime}$-dAdo generated with (A) natural abundant SAM; (B) [adenosyl-5',5" $-\mathrm{D}_{2}$ ]-SAM; (C) [adenosyl-2,8- $\mathrm{D}_{2}-1^{\prime}$, $2^{\prime}, 3^{\prime}, 4^{\prime}, 5^{\prime}, 5^{\prime \prime}-\mathrm{D}_{6}$ ]-SAM; (D) $5^{\prime}$-dAdo - with [adenosyl- ${ }^{13} \mathrm{C}_{10},{ }^{15} \mathrm{~N}_{5}$ ]-SAM; E, $5^{\prime}$-dAdo - with [adenosyl- $5^{\prime}-{ }^{13} \mathrm{C}$ ]-SAM. Features associated with the minor photolysis products are revealed in spectra of isotopologues $(\mathrm{B}, \mathrm{C})$ and indicated by (*). F, Q-band EPR, $5^{\prime}$-dAdo. generated with natural abundant SAM; the additional line width at low field is attributable to g/ $A$ strain. Simulations: Generated with EasySpin ${ }^{31}$ using a $5^{\prime}$-dAdo model with parameters listed in Table 1. EPR conditions: microwave frequency, $9.38 \mathrm{GHz}(\mathrm{A}-\mathrm{C}$ and G) and $34 \mathrm{GHz}$ (D-F); modulation, $10 \mathrm{G}$; T, 40 K. Simulations: generated with Easyspin ${ }^{31}$ using a $5^{\prime}$-dAdo model with parameters listed in Table 1. G, Q-band CW ${ }^{13} \mathrm{C}$ ENDOR of $5^{\prime}$-dAdo. From 11 to $15 \mathrm{MHz}$, generated with [adenosyl- ${ }^{13} \mathrm{C}_{10},{ }^{15} \mathrm{~N}_{5}$ ]-SAM where $(\boldsymbol{\nabla})$ represents ${ }^{13} \mathrm{C}$ Larmor frequency and the "goalpost" connecting the doublet from $1{ }^{\prime}-{ }^{13} \mathrm{C}$ and/or $2^{\prime}-{ }^{13} \mathrm{C}$, split by $A=0.8 \mathrm{MHz}$ (see eq 1). From 27 to $170 \mathrm{MHz}$, generated with [adenosyl- ${ }^{13} \mathrm{C}_{10},{ }^{15} \mathrm{~N}_{5}$ ]-SAM where $(O)$ represents $A / 2$ and only the high-frequency members of the doublets for $3{ }^{\prime}-{ }^{13} \mathrm{C}$ and $5^{\prime}-{ }^{13} \mathrm{C}$ are seen, as indicated, separated from their respective $A / 2$ by ${ }^{13} \mathrm{C}$ Larmor frequency. Spectrum between 70 and $149 \mathrm{MHz}$ also seen when generated from [adenosyl- $5^{\prime}-{ }^{13} \mathrm{C}$ ]-SAM. It is overlaid on the signal from ${ }^{1} \mathrm{H}$ of $\mathrm{C} 4{ }^{\prime}$ and $5^{\prime}$ in the spectrum with natural-abundance SAM (gray line). CW ENDOR conditions: microwave frequency, $34.8 \mathrm{GHz}$; modulation, $2 \mathrm{G}$; $T, 2 \mathrm{~K}$. 


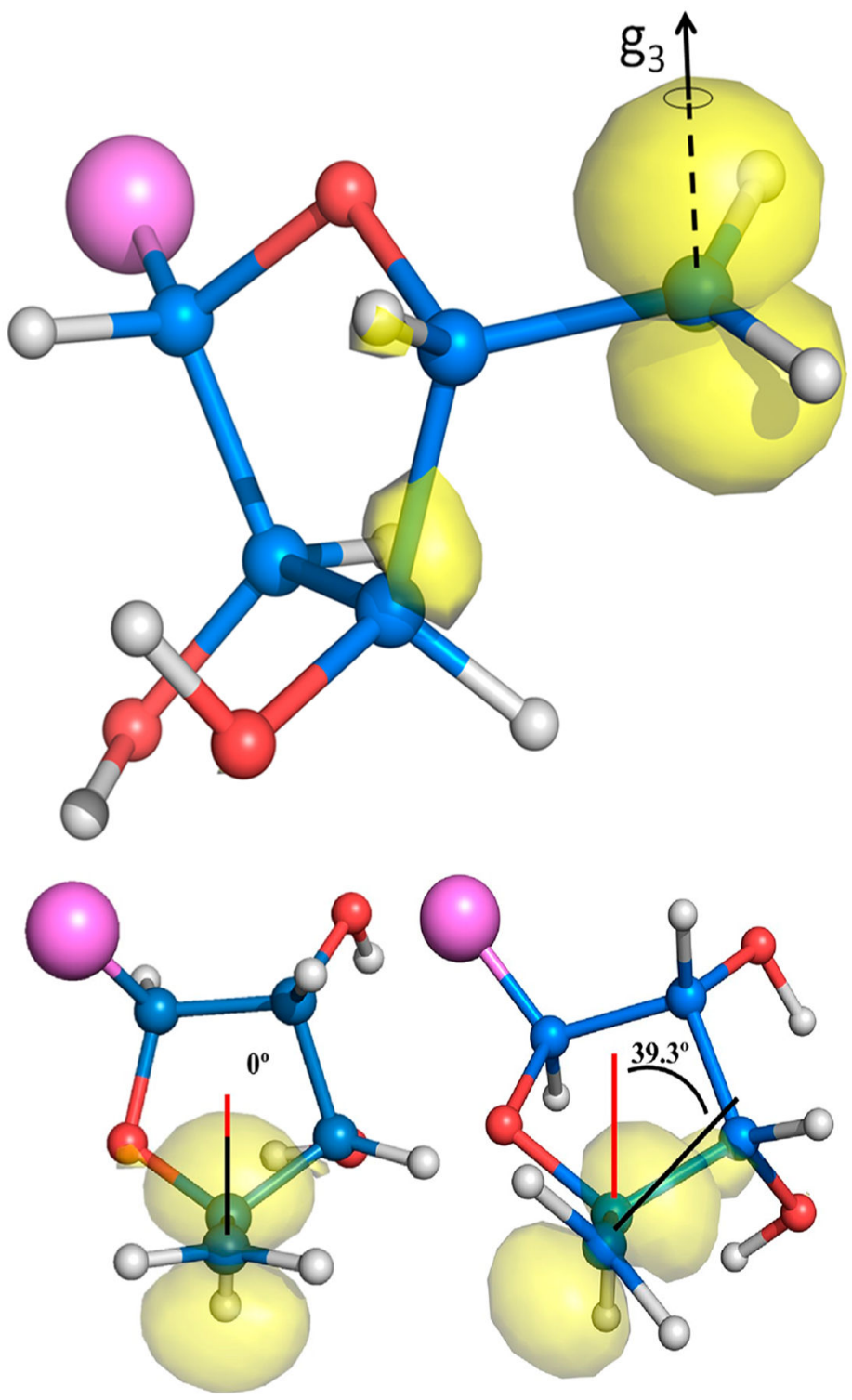

Figure 4.

DFT models of $5^{\prime}$-dAdo. Top: Perspective view of the optimized structure. Adenosine is represented by a violet sphere; the isosurface plot of the calculated HOMO (yellow) uses an isodensity of 0.08 au and shows the direction of $\mathrm{g}_{3}$ normal to the $\mathrm{C}^{\prime}{ }^{\prime} \mathrm{H}_{2}$ plane. Bottom: left, conformer with a dihedral "twist" at the $\mathrm{C}^{\prime}-\mathrm{C} 4$ ' bond, $\varphi=0$; right, optimized structure geometry $\varphi=39.3^{\circ}$. 


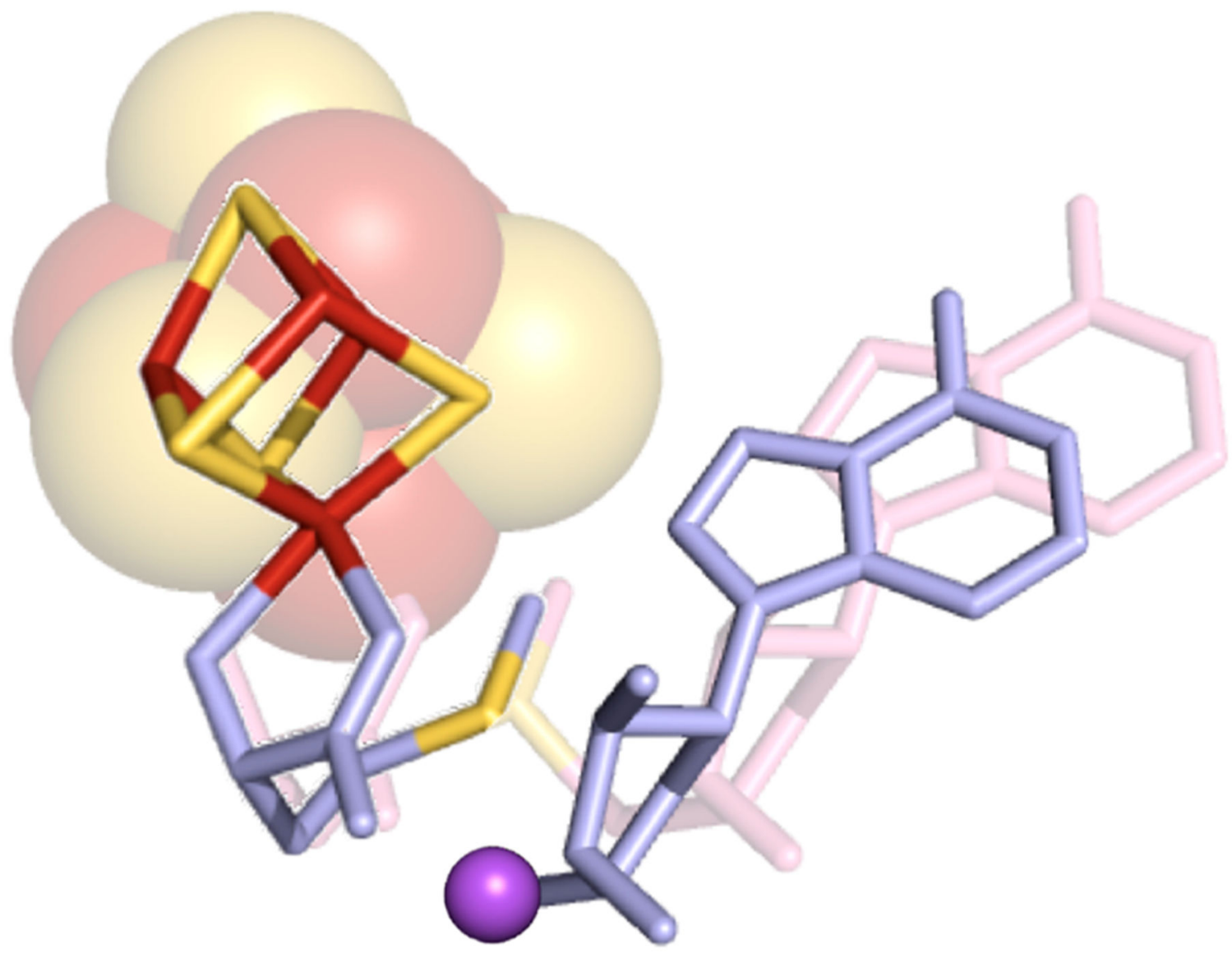

Figure 5.

Cartoon illustrating the proposed movement of $5^{\prime}$-dAdo upon $\mathrm{S}-\mathrm{C}\left(5^{\prime}\right)$ bond cleavage, as inferred from EPR and ENDOR data, based on PDB ID $3 \mathrm{CB} 8 ;^{38}\left[-\mathrm{C} 5^{\prime}(\mathrm{H})_{2}\right]$ is shown as a purple ball. 
Table 1.

Hyperfine Tensors (MHz) of $5^{\prime}$-dAdo from the Experiment ${ }^{a}$ Plus DFT-Computed Values in Parentheses, ${ }^{b}$ with Reference Values for Radicals Generated from Malonic Acid $^{c}$

\begin{tabular}{lccc}
\hline \multicolumn{1}{c}{$\mathbf{5}^{\prime}-\mathbf{d A d o} \cdot$} & $\boldsymbol{A}_{\mathbf{1}}$ & \multicolumn{1}{c}{$\boldsymbol{A}_{\mathbf{2}}$} & $\boldsymbol{A}_{\mathbf{3}}$ \\
$5^{\prime}-\mathrm{C}-{ }^{1} \mathrm{H} 0 a_{\mathrm{a}}$ & $-15(-28)$ & $-105(-104)$ & $-60(-63)$ \\
$5^{\prime}-\mathrm{C}-{ }^{1} \mathrm{H} a_{\mathrm{b}}$ & $-20(-25)$ & $-95(-101)$ & $-60(-61)$ \\
$4^{\prime}-\mathrm{C}-{ }^{1} \mathrm{H} \beta$ & $+80(+90)$ & $+80(+90)$ & $+110(+105)$ \\
$5^{\prime}-{ }^{13} \mathrm{C} a$ & $+10(+2)$ & $+10(+3)$ & $+230(+240)$ \\
$4^{\prime}-{ }^{13} \mathrm{C}$ & $60(+69)$ & $80(+86)$ & $60(+68)$ \\
$3^{\prime}-{ }^{13} \mathrm{C}$ & $40(-36)$ & $40(-33)$ & $50(-37)$ \\
$1^{\prime}-$ or $2^{\prime}-{ }^{13} \mathrm{C}$ & 0.8 & 0.8 & 3 \\
$\cdot \mathbf{C H}(\mathbf{C O O H})_{2} \boldsymbol{c}$ & $\boldsymbol{A}_{\mathbf{1}}$ & $\boldsymbol{A}_{\mathbf{2}}$ & $\boldsymbol{A}_{\mathbf{3}}$ \\
${ }^{1} \mathrm{H} \boldsymbol{a}$ & -91 & -29 & -58 \\
${ }^{13} \mathrm{Ca}$ & +22.8 & +42.2 & +212.7 \\
$\cdot \mathbf{C H}(\mathbf{C O O H})$ & $\boldsymbol{A}_{\mathbf{1}}$ & $\boldsymbol{A}_{\mathbf{2}}$ & $\boldsymbol{A}_{\mathbf{3}}$ \\
${ }^{1} \mathrm{H} \boldsymbol{a}_{\mathrm{a}}$ & -30 & -55 & -91 \\
${ }^{1} \mathrm{Ha} a_{\mathrm{b}}$ & -37 & -59 & -92 \\
\hline
\end{tabular}

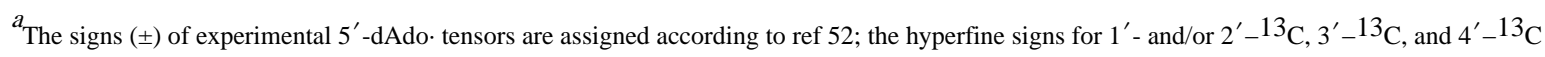
are not determined. The simulations employ $\mathrm{g}=[2.0075,2.0015,2.000]$ ( $\mathrm{gave}=2.003$ ) and tabulated hyperfine couplings. The $A 3$ components for ${ }^{1} \mathrm{H} a_{\mathrm{a}}$ and ${ }^{1} \mathrm{H} a_{\mathrm{b}}$ are parallel to $\mathrm{g}_{3}$ and normal to the $\mathrm{C}^{\prime}{ }^{\prime} \mathrm{H} 2$ plane (see Figure 3 ) as seen in refs 54 and 55 . For ${ }^{1} \mathrm{H} a_{\mathrm{a}}, \mathrm{A}_{1} \| \mathrm{g}_{1}$; simulation required the ${ }^{1} \mathrm{H}_{\mathrm{b}}$ tensor be rotated relative to that of ${ }^{1} \mathrm{H} a_{\mathrm{a}}$ by an angle approaching $a \sim 120^{\circ}$ expected for sp ${ }^{2}$ hybridized $\mathrm{C} 5^{\prime}$ and found by DFT optimization, but because of the small g-anisotropy, this angle could be allowed to vary over the range $90^{\circ} \lesssim \alpha \lesssim 120^{\circ}$. A3 for $4^{\prime}-\mathrm{C}-{ }^{1} \mathrm{H} \beta$ makes an angle of $\sim 40^{\circ}$ with respect to $\mathrm{g} 3$. The EPR simulations tightly constrain the values of the tensor components; for strongly coupled nuclei (all but $1^{\prime}-$ and/or $2^{\prime}-13 \mathrm{C}$ ), numerous simulations indicate that one tensor component value may vary by as much as $\pm 5 \mathrm{MHz}$, but the sum of multiple variations must also be no more than roughly $\pm 5 \mathrm{MHz}$. Additional EasySpin simulation parameters: EPR line width, $36 \mathrm{MHz}$ (X-band); $45 \mathrm{MHz}$ (Q-band). Hyperfine strain parameters employed to account for unresolved hyperfine coupling: [30, 10, 10] MHz for A-C, E, and F; [30, 10, 40] MHz for D. The simulation for D is the sum of $80 \%{ }^{13} \mathrm{C} 5^{\prime}$-dAdo. and $20 \%{ }^{12} \mathrm{C}$, and for $\mathrm{E}$, it is the sum of $85 \%{ }^{13} \mathrm{C} 5^{\prime}$-dAdo. and $15 \%{ }^{12} \mathrm{C}$.

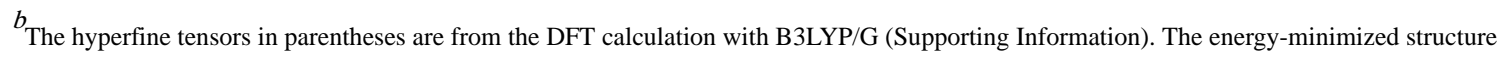
(Figure 4) has equivalent $\mathrm{C} 5^{\prime}-\mathrm{H}$ bonds and ${ }^{1} \mathrm{H}$ hyperfine tensors, whereas the experiment gives slightly different tensors for the two. We attribute the observed inequivalence to a slight desymmetrization due to interactions in the enzyme active site that are absent in the computation.

${ }^{c_{1}} \mathrm{H}$ and ${ }^{13} \mathrm{C}$ tensors for $\cdot \mathrm{CH}(\mathrm{COOH}) 2$ formed by irradiation of malonic acid, taken from McConnell et al. ${ }^{55}$ and Cole and Heller, ${ }^{56}$ respectively. ${ }^{1} \mathrm{H}$ tensors for $\cdot \mathrm{CH}_{2}(\mathrm{COOH})(\mathrm{g}=[2.0042,2.0034,2.0020]$, gave $=2.0032)$ formed by irradiation of malonic acid; see ref 54 . The somewhat greater inequivalence between the hyperfine tensors for two $a$-type ${ }^{1} \mathrm{H}$ of $5^{\prime}$-dAdo and $\cdot \mathrm{CH}_{2}(\mathrm{COOH})$ likely reflects the influence of contacts with the surrounding residues, as does the observation that the two radicals have the same gave yet differ in their in-plane g-values, $g_{1}$ and g2.

J Am Chem Soc. Author manuscript; available in PMC 2019 October 09. 